\title{
THE
}

\section{Transcranial focal electrical stimulation via concentric ring electrodes in freely moving cats: Antiepileptogenic and postictal effects}

\author{
Alejandro Valdés-Cruz \\ Benjamín Villasana-Salazar \\ Brandon Williams \\ David Martínez-Vargas
}

Víctor Manuel Magdaleno-Madrigal

Follow this and additional works at: https://digitalcommons.uri.edu/ele_facpubs

The University of Rhode Island Faculty have made this article openly available.

Please let us know how Open Access to this research benefits you.

This is a pre-publication author manuscript of the final, published article.

Terms of Use

This article is made available under the terms and conditions applicable towards Open Access Policy Articles, as set forth in our Terms of Use.

\section{Citation/Publisher Attribution}

Valdés-Cruz, A., Villasana-Salazar, B., Williams, B., Martínez-Vargas, D., Magdaleno-Madrigal, V. M., Almazán-Alvarado, S., \& Besio, W. G. (2019). Transcranial focal electrical stimulation via concentric ring electrodes in freely moving cats: Antiepileptogenic and postictal effects. Experimental Neurology, 320, 113012. doi: 10.1016/j.expneurol.2019.113012

Available at: https://doi.org/10.1016/j.expneurol.2019.113012

This Article is brought to you for free and open access by the Department of Electrical, Computer, and Biomedical Engineering at DigitalCommons@URI. It has been accepted for inclusion in Department of Electrical, Computer, and Biomedical Engineering Faculty Publications by an authorized administrator of DigitalCommons@URI. For more information, please contact digitalcommons-group@uri.edu. 
Authors

Alejandro Valdés-Cruz, Benjamín Villasana-Salazar, Brandon Williams, David Martínez-Vargas, Víctor Manuel Magdaleno-Madrigal, Salvador Almazán-Alvarado, and Walter Besio

This article is available at DigitalCommons@URI: https://digitalcommons.uri.edu/ele_facpubs/94 


\title{
Transcranial focal electrical stimulation via concentric ring electrodes in freely moving cats: Antiepileptogenic and postictal effects
}

\author{
Alejandro Valdés-Cruz ${ }^{\mathrm{a}, *}$, Benjamín Villasana-Salazar ${ }^{\mathrm{a}}$, Brandon Williams ${ }^{\mathrm{b}}$, David Martínez-Vargas ${ }^{\text {a }}$, \\ Víctor Manuel Magdaleno-Madrigal a ${ }^{\text {a }}$ Salvador Almazán-Alvarado ${ }^{\mathrm{a}}$, Walter G. Besio ${ }^{\mathrm{b}}$ \\ ${ }^{a}$ Laboratorio de Neurofisiología del Control y la Regulación, Dirección de Neurociencias, Instituto Nacional de Psiquiatría Ramón de la Fuente Muñiz, México, Calz. México-Xochimilco 101, Col. \\ San Lorenzo Huipulco. Tlalpan, México City Zip Code 14370, Mexico \\ bepartment of Electrical, Computer \& Biomedical Engineering, University of Rhode Island, Kingston, RI 02881, USA
}

\section{A R T I C L E I N F O}

\section{Keywords:}

Transcranial focal electrical stimulation

Tripolar concentric ring electrodes

Electrical amygdaloid kindling

Epileptogenesis

Kindling development inhibition

\begin{abstract}
A B S T R A C T
Transcranial focal electrical stimulation (TFS) via tripolar concentric ring electrodes (TCRE), tripolar TFS, is proposed to treat pharmacoresistant epilepsy. We determined the effect of tripolar TFS on electrical amygdaloid kindling (AK) in freely moving cats. Fifteen cats were bilaterally implanted with electrodes in the amygdala (AM) and prefrontal cortex and assigned to three groups: the control group, which only received AK; the tripolar TFS before AK group, in which TCREs were placed over the vertex and tripolar TFS $(300 \mathrm{~Hz}, 200 \mu$ s biphasic equal charge, square pulses) was delivered for $40 \mathrm{~min}$ just prior to AK; and the tripolar TFS after AK group, in which the TCREs were placed over the temporal bone ipsilateral to the kindled AM, while tripolar TFS was administered for 2 min just after AK onset for 40 days, and, thereafter, only AK was applied. AK was applied daily until all animals reached kindling stage VI. A three concentric spheres finite element cat head model was developed to analyze the electric fields caused by tripolar TFS. Tripolar TFS after AK inhibited kindling development. Animals with tripolar TFS after AK remained at the focal seizure stages for 20 days after tripolar TFS cessation and required 80.0 \pm 15.42 AK stimulations to reach stage VI, significantly higher than TFS before AK, and control $(P<.001)$. Tripolar TFS before AK did not show signs of protection against epileptogenesis. The finite modeling of tripolar TFS showed that the electric field is $>0.3 \mathrm{mV} / \mathrm{mm}$ at depths less than approximately $12.6 \mathrm{~mm}$ in the cat brain, which should be strong enough to alter brain activity. In conclusion, tripolar TFS applied via a TCRE over the ipsilateral temporal area significantly delayed AK. This taken together with other reports of tripolar TFS aborting seizures in acute seizure models suggests that tripolar TFS is a promising new modality that should be considered for further testing.
\end{abstract}

\section{Introduction}

Temporal lobe epilepsy is a chronic neurological disorder characterized by a high resistance to pharmacological treatments (Pitkänen and Sutula, 2002). Epilepsy surgery is a possible option but not all patients are candidates for surgery (Ryvlin et al., 2014), and patients sometimes exhibit surgical complications (Rolston et al., 2016). Associated functional deficits such as language or motor impairment often limit resection, especially in seizures arising from eloquent cortex. Moreover, bilateral or multiple seizure foci are generally not amenable to surgery (Duncan and Hamani, 2015).

Electrical stimulation methods, such as vagus nerve stimulation, an established form of extracranial neurostimulation (Gooneratne et al., 2016), deep brain stimulation (DBS), have shown positive efficacy in humans (Fisher and Velasco, 2014). However, adverse effects of these treatments have been described (Appleby et al., 2007; Kotagal, 2011). In an exhaustive literature review, DBS in the anterior nucleus of the thalamus was described to have provoked infection (10.0\%), intracranial hemorrhage (4.5\%), depression (37.3\%), and memory impairment (27.3\%); meanwhile, vagus nerve stimulation provoked local inflammation (3.3\%), intolerable chronic cough $(3.3 \%)$, hoarseness $(22 \%)$, varying degrees of vagus nerve injury (2.8\%), and throat discomfort (8\%) (Gooneratne et al., 2016).

Non-invasive stimulation treatments have emerged to modulate several brain disorders, including epilepsy. These treatments, which include transcranial magnetic stimulation and transcranial direct current stimulation, have shown beneficial long-term effects on seizure control in patients with epilepsy

Abbreviations: AD, afterdischarge; AM, amygdala; AK, amygdaloid kindling; CSF, cerebrospinal fluid; SE, status epilepticus; TFS, transcranial focal electrical stimulation; TCRE, tripolar concentric ring electrodes; tDCS, transcranial direct current stimulation..

* Corresponding author.

Email addresses: alevalc@imp.edu.mx (A. Valdés-Cruz); bwilliams3@my.uri.edu (B. Williams); davmv@imp.edu.mx (D. Martínez-Vargas); maleno@imp.edu.mx (V.M. Magdaleno-Madrigal); salmazan@imp.edu.mx (S. Almazán-Alvarado); besio@uri.edu (W.G. Besio) 
(Faria et al., 2012; Santiago-Rodríguez et al., 2008) and in experimental animal models of temporal lobe epilepsy (Kamida et al., 2011; Shojaei et al., 2014). Despite these non-invasive antiepileptic treatments, the best structures to stimulate and the most effective stimuli to use are still unknown (Theodore and Fisher, 2007).

Transcranial focal electrical stimulation (TFS) via tripolar concentric ring electrodes (TCRE) is a non-invasive experimental paradigm to treat pharmacoresistant epilepsy. This electrical stimulation treatment uses the TCRE, which provide a more uniform current density compared with conventional disc electrodes (van Oosterom and Strackee, 1983) and focus the electrical stimulation directly below the electrode leading to the induction of electric fields even in subcortical structures (Besio et al., 2011a) without compromising the skin surface or cognitive processes in the rat (Besio et al., 2010b; Rogel-Salazar et al., 2013).

TFS has demonstrated efficacy in the modulation of seizure activity in rats with acute models of epilepsy, such as through pentylenetetrazole and penicillin (Besio et al., 2011b). TFS applied after pilocarpine-induced status epilepticus (SE) increased the survival rate of the rats and induced electrographic changes. Additionally, there was a reduction in the highly synchronized brain activity within the beta and gamma bands (Besio et al., 2007; Santana-Gómez et al., 2015), suggesting a long-lasting effect of TFS on brain activity. TFS administered before the onset of pilocarpine-induced SE plus a sub-effective dose of diazepam resulted in a diminished severity of convulsive seizures and SE, an augmented latency to convulsive seizures and SE, and suppression of the hippocampal neuronal damage induced by pilocarpine (Besio et al., 2013).

Despite the reported benefits, all previous experiments have been performed on rats, and the effects of TFS on epileptogenesis are still unknown. In this study, we used the electrical amygdaloid kindling (AK) model of temporal lobe epilepsy epileptogenesis, which consists of repeated and periodic electrical stimulations to limbic brain structures, progressively leading to the induction of an electroencephalographic afterdischarge (AD) and focal and secondarily generalized seizures (Sato et al., 1990).

Electrical stimulation techniques are accessible in equipment and cost, but require extensive investigation of the effects of time-targeted electrical perturbation of epileptic seizures in animal experiments. Importantly, most studies have not expanded beyond the acute effects of the treatment. Given the chronic nature of the epileptic process in the majority of patients, understanding of the long-term effects of a stimulation paradigm is critical (Kozák and Berényi, 2017). Also, there is an obvious and persistent need for animal experimental studies in epilepsy research to improve our knowledge about pathophysiological mechanisms and provide valuable information for target and biomarker identification, taking into account the broad range of epilepsy types and etiologies (Möller et al., 2018). The kindling model is a chronic model that is currently used by antiepileptic drug discovery programs, including the NIH/NINDS-sponsored anticonvulsant drug development program in the U.S., and adequately predicts the clinical utility of novel antiepileptic drugs against partial seizures in patients with epilepsy (Bialer and White, 2010; Löscher, 2011). This chronic model of epileptogenesis provides an opportunity to study the focal activation of a specific stimulated brain area and the gradual development of seizures in a larger animal model (Gorter et al., 2015). Thus, the aim of our study was to investigate the effect of TFS application via TCREs stimulating extracranially on convulsive activity and epileptogenesis induced by AK in cats.

\section{Methods}

\subsection{Animals}

Fifteen freely moving adult male cats weighing 3.00-5.00 Kg were used. The experiments were undertaken following the technical guidelines for the production, care and use of animals in the laboratory issued by SAGARPA (NOM-062-ZOO- 1999) and were approved by the Ethics Committee of the In- stituto Nacional de Psiquiatría Ramón de la Fuente Muñiz. Furthermore, attempts were made to minimize the number of animals used in the study and their suffering.

\subsection{Surgery}

Surgery was performed under isoflurane anesthesia $\left(5 \%\right.$ in $\mathrm{O}_{2}$ for induction and $2 \%$ for maintenance). A mixture of ketamine hydrochloride $(40 \mathrm{mg} / \mathrm{kg})$ and xylazine hydrochloride $(5 \mathrm{mg} / \mathrm{kg})$ was employed as a pre-anesthetic, followed by an analgesic (Butorphanol, $0.4 \mathrm{mg} / \mathrm{kg}$ ). Stainless steel bipolar electrodes were stereotaxically implanted (Snider and Niemer, 1961), oriented to both amygdalae (AM) (AP + 11.5, L 9.5, $H$ 15.0). Epidural electrodes were implanted in both prefrontal cortices for electrographic recording. In addition, TCREs ( $10 \mathrm{~mm}$ diameter) were fixed over the skull. In the TFS before AK group, one TCRE was centered on the vertex $(A P+12.0)$. In the TFS after AK group, one TCRE was fixed over the temporal bone (AP +11.5, L 5.5), ipsilateral to the kindled AM. In the control group, the TCREs were not placed, and the cats did not receive TFS.

All electrodes were soldered into two connectors: TCRE in a DB9 connector and other electrodes and grounds in a DB25 connector. The entire preparation was fixed to the skull with dental acrylic. After the surgery, animals were treated with antibiotics and analgesics. Cats were allowed to recover for 15 days in sound-isolated chambers used for electrographic recordings and were provided with water and food ad libitum.

\subsection{Electrical stimulation}

To determine the AK and tripolar TFS electrical stimulation thresholds, a S88X stimulator was used (Grass, Massachusetts, USA). For the AK $(60 \mathrm{~Hz}, 1 \mathrm{~ms}$ monophasic square pulses for $1 \mathrm{~s})$, stimulation was started at $100 \mu \mathrm{A}$, and repeated every $10 \mathrm{~min}$, the intensity was gradually augmented by $50 \mu \mathrm{A}$ until animals presented ipsilateral eyeblink accompanied by a brief AD (1-2s). For tripolar TFS ( $300 \mathrm{~Hz}, 200 \mu$ s biphasic square pulses), the electrode impedances between the outer ring and disc of the TCRE were $<10 \mathrm{~K} \Omega$. Tripolar TFS was applied in 1-min trains every $10 \mathrm{~min}$ through the outer ring (external diameter of $10 \mathrm{~mm}$ ) and disc of the TCRE (with the middle ring floating) started at $1 \mathrm{~mA}$; the intensity was gradually augmented by $0.5 \mathrm{~mA}$ until animals showed blinking and a decrease in electrographic voltage. Electrical stimulation was started the following day, all groups received AK stimulation every $24 \mathrm{~h}$. In the TFS before AK group, tripolar TFS was applied for 40 min prior to AK. In TFS after AK group, tripolar TFS was administered for 2 min after the AK onset for 40 days, and then, only AK was applied. The control group only received AK stimulation. This procedure continued until all animals exhibited three consecutive kindling stage VI seizures, according to the following classification scheme (Wada and Sato, 1974): Stage I, ipsilateral facial contractions; Stage II, bilateral facial contractions; Stage III, vertical head movements; Stage IV, walking in circles; Stage V, generalized myoclonus in all four limbs; and Stage VI, tonic-clonic generalized seizures. All animal behavior was recorded on videotape during AK and behavioral seizures. The videos were analyzed offline by two blinded observers.

\subsection{Electrographic recordings}

Electrographic activity was recorded while cats were in a vigilance state of quiet awake using 78E polygraphic equipment (Grass, Massachusetts, USA), preamplified and band-pass filtered between 3 and $300 \mathrm{~Hz}$, and acquired on-line (500-Hz sampling frequency) using an ana$\log$ to digital conversion system. (ADQ8CH). Signal analysis was conducted off-line using a computational program. Both, the analog to digital conversion system and the software were developed in our laboratory for electrographic analysis (Valdés-Cruz et al., 2008, 2012). 


\subsection{Histological verification}

At the end of the experiment, the animals were euthanized with an overdose of sodium pentobarbital $(100 \mathrm{mg} / \mathrm{kg}$, I.V.) and perfused intracardially. The brains were dissected, and Nissl staining was performed. Only animals with correct electrode placements within the AM complex were included in the study.

\subsection{Finite element modeling of TFS}

A three concentric spheres finite element cat head model was developed to investigate the effects of TFS using the AC/DC module of Comsol Multiphysics v4.2 (Comsol, Inc., Birmingham, MA). The three concentric spheres represented the skull, cerebrospinal fluid (CSF), and the brain. The dimensions of our FEM are half the size of the human head model used by Rush and Driscoll (1969). The layers were modeled as homogeneous and isotropic with the properties of the skull, CSF, and brain with radii of: $42.5,40,38.5(\mathrm{~mm})$ and electrical conductivities (S/ $\mathrm{m}$ ) of: 0.018, 1.76, and 0.25, respectively (Geddes and Baker, 1967). We modeled a $10 \mathrm{~mm}$ diameter TCRE for tripolar TFS and applied $2.5 \mathrm{~mA}$ between the outer ring and central disc. According to Francis, Gluckman, and Schiff, peak electric fields as weak as $0.298 \mathrm{mV} / \mathrm{mm}$ can synchronize neural networks, and even activate single neurons occasionally (Francis et al., 2003). Therefore, we used a threshold peak electric field of $0.3 \mathrm{mV} / \mathrm{mm}$ to signify when neural networks would be activated.

For comparison, two configurations of two conventional electroencephalography $10 \mathrm{~mm}$ diameter disc electrodes were also performed using the same model, a) the discs were separated the same distance as the outer ring and central disc of the TCRE $(3.0 \mathrm{~mm})$, and b) the disc electrodes were place 90 degrees apart on the sphere similar to transcranial direct current stimulation (tDCS). Typical tDCS intensity is 1.0 to $2 \mathrm{~mA}$. In our model if we used the same $2.5 \mathrm{~mA}$ stimulation with the disc electrodes that we used for tripolar TFS the model showed that nearly the entire brain region had electric fields $>0.3 \mathrm{mV} / \mathrm{mm}$, suggesting activation. Since the stimulation is applied to the skull rather than the scalp, for the disc electrode models, we reduced the stimulation intensity to one-tenth that of the tripolar TFS, $0.25 \mathrm{~mA}$, applied between the two electrodes. This was done in attempt to compare focality of tripolar TFS to disc electrode stimulation such as tDCS.

\subsection{Statistical analysis}

Statistical analysis of group differences in AK variables were performed by one- way analysis of variance (ANOVA) and two-way ANOVA for repeated measures, experimental group, and AK trials as a repeated measure, followed by the Tukey post hoc test. The significance level was set to $P<.05$. Data are presented as the mean \pm standard deviation of the mean. Statistical analysis was carried out using SPSS 20 for Windows.

\section{Results}

The histological verification revealed that the stimulation electrodes in all animals were located within the AM complex (Fig. 1). The AK threshold intensity used was $300-500 \mu \mathrm{A}$ and was kept constant until the animals were fully kindled. For tripolar TFS, the threshold intensity was $2.5 \mathrm{~mA}$ in all TFS-treated animals.

Effect of tripolar transcranial focal electrical stimulation on electrical amygdaloid kindling.

Tripolar TFS after AK-treated animals reached stage VI after $80.0 \pm 15.42$ AK stimulations; tripolar TFS before AK-treated animals after $24.6 \pm 6.8$, and control animals after $25.4 \pm 2.7$. Tripolar TFS after AK application significantly retarded the fully kindled state compared to the progression in control animals, and those treated with tripolar TFS before AK $(P<.001)$ (Fig. 2). Analyses of the stepwise progression of AK were performed by calculating the number of kindling trials in each seizure stage. A significant increase in kin-

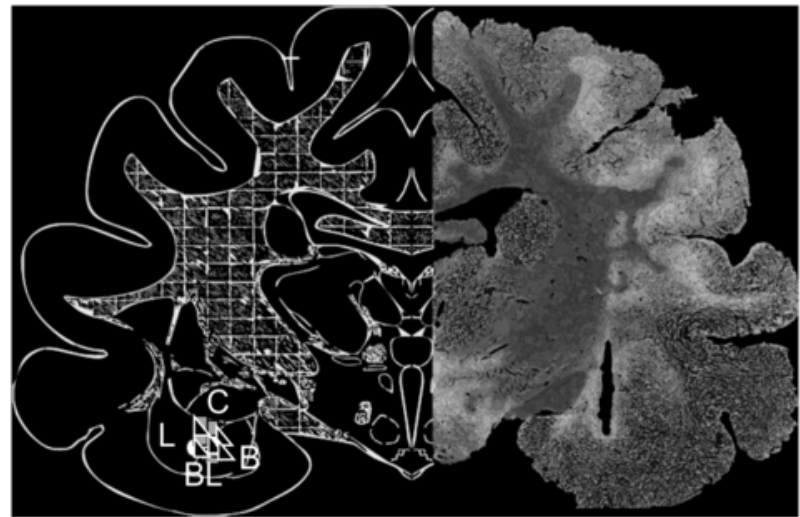

Fig. 1. Locations of the tips of the stimulating electrodes based on histological verification. White circles, Control group; gray squares, tripolar TFS before AK group; black triangles, tripolar TFS after AK group. Amygdala nuclei: BL, basolateral; C, central; L, lateral.

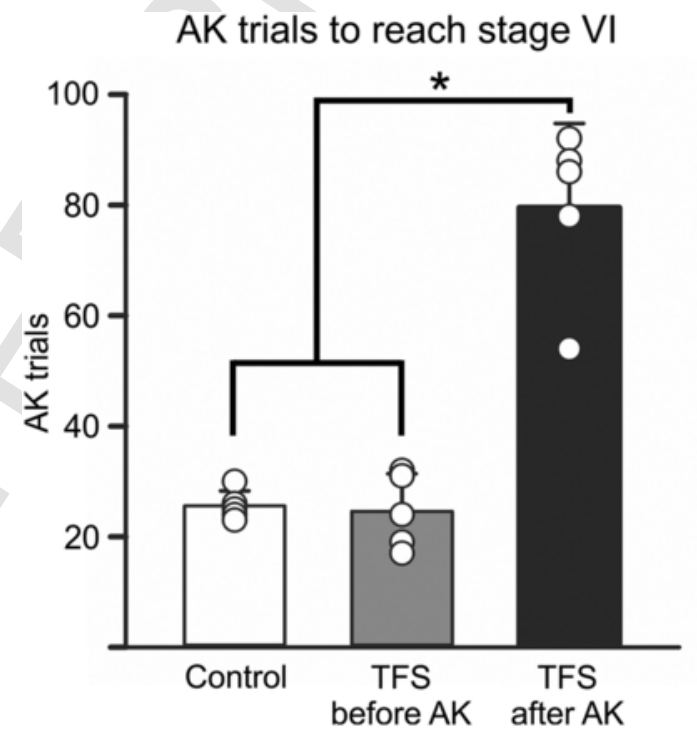

Fig. 2. Comparison of the mean kindling rate to the first stage VI amygdaloid kindling event of the three groups. Note that the animals with tripolar TFS after AK required a large number of AK trials to reach this stage.

dling stage II was observed in tripolar TFS after AK animals $(38.4 \pm 19.62)$ compared to that seen in animals treated with tripolar TFS before AK $(2.4 \pm 1.94)$, and control $(\mathrm{P}<.001)$ (Fig. 3A). Furthermore, on seizures electrographic analysis, the tripolar TFS before AK group had a significantly longer $\mathrm{AD}$ duration in Stage II $(26.99 \mathrm{~s} \pm 18.61)$ than the tripolar TFS after AK group $(7.95 \mathrm{~s} \pm 1.76)$ $(P<.05)$ (Fig. 3B). Additionally, this group showed a significantly higher AD frequency (spikes per second) than the tripolar TFS after AK group in behavioral stage IV $(\mathrm{P}<.05)$, and stage $\mathrm{V}(P<.02)$ (Fig. $3 \mathrm{C})$.

For the epileptogenesis analysis, tripolar TFS after AK application significantly delayed the progression of behavioral seizure stages compared to control $(\mathrm{P}<.02)$, and tripolar TFS before AK $(P<.03)$ (Fig. $4 \mathrm{~A})$; and decreased the $\mathrm{AD}$ duration during kindling acquisition compare to tripolar TFS before AK $(P<.01)$ (Fig. 4B). In both progression of behavioral seizure stages, and $\mathrm{AD}$ duration, two-way ANOVA for repeated measures showed significant differences by K-trials, and K-trials and Group $(\mathrm{P}<.001)$. Since some of the subjects in the control, and tripolar TFS before AK groups, showed stage VI seizures after 19 trials, the analysis was performed from kindling trials 1 to 19.

The tripolar TFS before AK group stimulated over the vertex did not show any anticonvulsant effect on AK, exhibiting a similar behavioral evolution of kindling as control animals. Also, this protocol induces an increase in electrographic seizures severity. In contrast, cats that had tripolar TFS after AK application remained at the focal seizure stage, Stage II, for approximately 20 days 

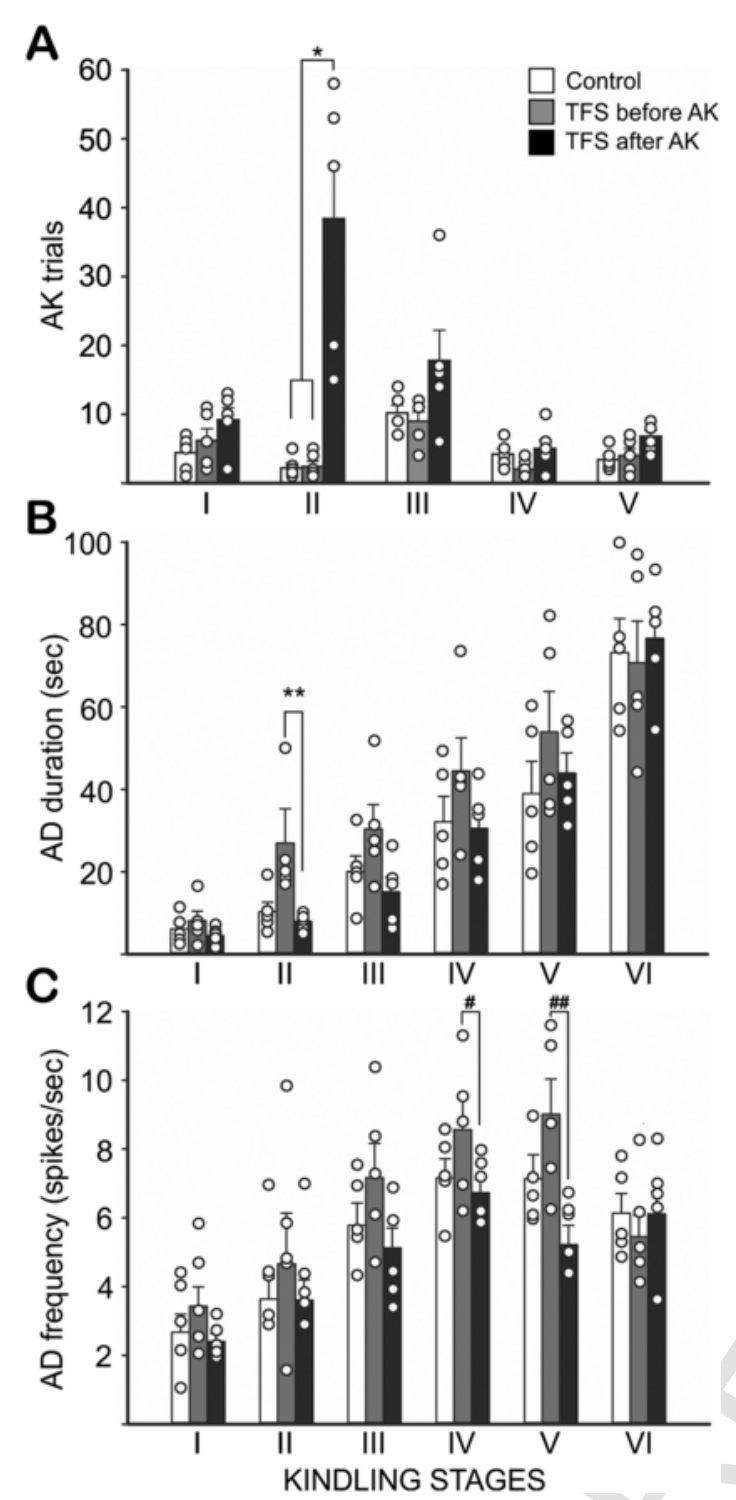

Fig. 3. A) The mean number of stimulations for the evolution of the behavioral stages (I $-\mathrm{V}$ ) of AK in all groups. Note a significant increase in the number of stimulations in stage II in the tripolar TFS after AK group. B) Afterdischarge duration in the stage I-VI seizures of all experimental groups. Note, a significant increase in the stage II of the tripolar TFS before AK group compare to that of the tripolar TFS after AK group. C) Afterdischarge frequency (spikes/s) in the stage I-VI seizures. Note a significant increase in stages IV and V in the tripolar TFS before AK group compared to the tripolar TFS after AK group. ${ }^{*} P<.001 ; * * P<.05,{ }^{* * * P}<.02$.
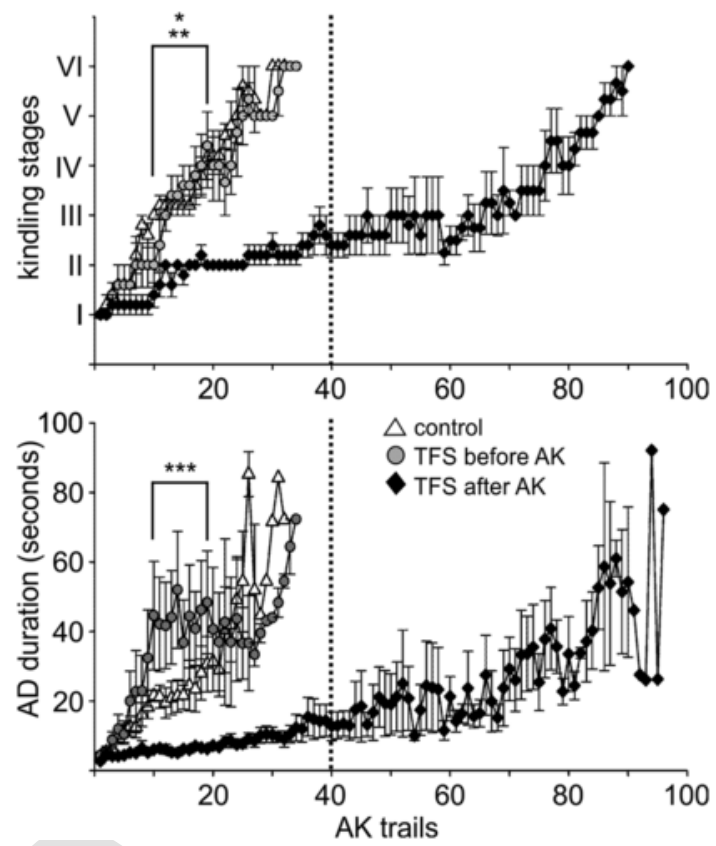

Fig. 4. A) Development of kindling seizure stages. Note that tripolar TFS after AK animals remained in stage II from AK trial 9 to AK trial 70. From AK trial 10 to 19 a significant difference was observed $\left({ }^{*} \mathrm{P}<.02\right.$ tripolar TSF after AK vs control, ${ }^{* *} P<.03$ tripolar TSF after AK vs tripolar TFS before AK). B) Daily afterdischarge (AD) duration. A regular progression of duration was observed in the control and tripolar TFS before AK groups. Note a significant difference from AK trial 10 to AK trial 19 compare tripolar TSF after AK vs tripolar TFS before AK $(* * * P<.01)$. Test was performed for the first 19 stimulations because some animals in the control and tripolar TFS before AK groups reached stage VI seizures at this point. The dotted line indicates the tripolar TFS cessation.

after the cessation of tripolar TFS, beyond the 40 AK stimulations alone. In addition, tripolar TFS before AK animals presented a long motionless period during the postictal electrographic recordings of the secondarily generalized seizures.

\subsection{Finite element modeling}

The three concentric spheres finite element head models allowed us to calculate, and visualize, what the electric fields were throughout the cat head models due to different electrode configurations. Fig. 5 shows symmetric 2D slices through the center of the three models, A) $10 \mathrm{~mm}$ dia. TCRE, B) two $10 \mathrm{~mm}$ dia. Disc electrodes spaced $3 \mathrm{~mm}$ apart, and C) two $10 \mathrm{~mm}$ dia. Disc electrodes spaced 90 degrees apart. The $y$-axis shows the relative distance from the midpoint of central disc and the $\mathrm{x}$-axis shows the relative depth from the surface of the scalp. From Fig. 5A the electric field is $>0.3 \mathrm{mV} / \mathrm{mm}$ at depths less than approximately $12.6 \mathrm{~mm}$ deep into the brain. Fig. 5A also shows how
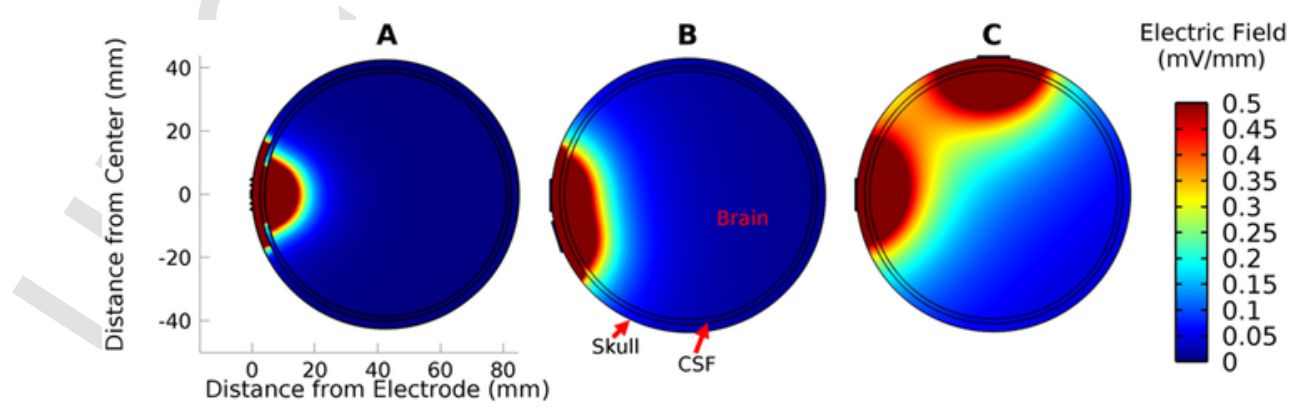

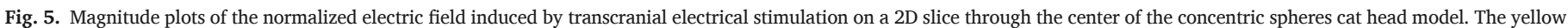

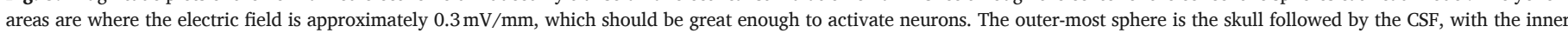

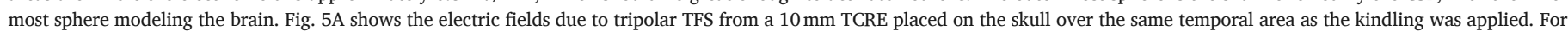

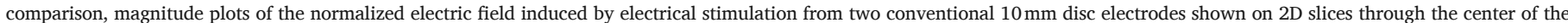

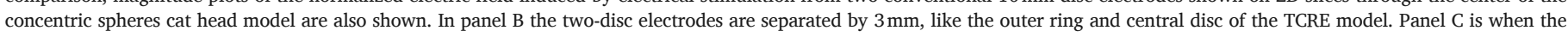

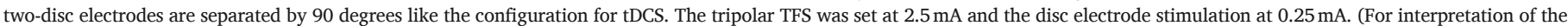
references to colour in this figure legend, the reader is referred to the web version of this article.) 
the electric field is symmetric below the $10 \mathrm{~mm}$ dia. TCRE. In Fig. 5B the electric field is not symmetrical, and even with only one-tenth the current intensity as the tripolar TFS, would activate a larger region of the brain. Further, in Fig. 5B the penetration depth is nearly the same as Fig. 5A. Fig. 5C clearly shows two distinct areas that would be affected by tDCS type stimulation directly around both electrodes. A much larger region in $5 \mathrm{C}$ than in $5 \mathrm{~A}$ would be activated.

\section{Discussion}

Our results provide evidence that tripolar TFS induced antiepileptogenic and anticonvulsant effects when the tripolar TFS was administered after the AK. In addition, a long-lasting suppressive effect was observed; in this way, the animals remained at the focal seizure stages of kindling for 20 days after tripolar TFS cessation, and approximately 80 AK stimulations were necessary to reach the stage VI of kindling. Furthermore, when tripolar TFS was administered before AK, the beneficial effects on epileptogenesis and seizures were not observed, conversely, it increased the severity of afterdischarge frequency and duration.

\subsection{Effect of tripolar TFS after AK on epileptogenesis development}

Tripolar TFS after AK induced a long-lasting protective effect against secondarily generalized seizures of at least 20-days. These antiepileptogenic and anticonvulsant effects are similar to those seen with other electrical stimulation methods, such as vagus nerve stimulation (Fernández-Guardiola et al., 1999), stimulation of the nucleus of the solitary tract (Magdaleno-Madrigal et al., 2002) and low-frequency stimulation of central piriform cortex (Yang et al., 2006).

The structures activated during the initial AK stages (I-II) include amygdala nuclei and the piriform, insular, perirhinal and endopiriform cortices. Neuronal activation of the piriform cortex and related sites are at least required for the timely development of generalized seizure activity (Sato et al., 1998). The electric field from the TCRE with $2.5 \mathrm{~mA}$ applied has the capacity to interfere in activating neurons at a depth shallower than $12.6 \mathrm{~mm}$ into the cat brain. According to our measurements, $12.6 \mathrm{~mm}$ into the brain is sufficient depth to reach deep mesial structures, such as piriform cortex, amygdala, and hippocampus. Nevertheless, complete protective mechanisms of the tripolar TFS still are unknow.

We used the commonly referenced adult head radius of $92 \mathrm{~mm}$ that Rush and Driscoll (1969) modeled, and assuming the cat head is half the size of the adult human, we arrived at the skull radius of $42.5 \mathrm{~mm}$. We modeled the electrodes on the skull. The skull thickness was set to $2.5 \mathrm{~mm}$ and the CSF was $1.5 \mathrm{~mm}$ thick, reducing the human dimensions in half as well. Comparing the electric fields from the two closely spaced disc electrodes model (Fig. 5B), that had $3 \mathrm{~mm}$ spacing the same as the $10 \mathrm{~mm}$ dia. TCRE, using one-tenth the current, $0.25 \mathrm{~mA}$, stimulation would activate a nonsymmetrical region that is larger than that of tripolar TFS, Fig. 5A. By separating the two-disc electrodes by 90 degrees, like a tDCS configuration, the $0.25 \mathrm{~mA}$ current generates electric fields that are great enough to activate an even larger region of the brain (Fig. 5C). Using the disc electrodes (Fig. 5B and C) generates electric fields that are far less focal than from the TCRE (Fig. 5A). By separating the disc electrodes 90 degrees it can be seen that there would be two regions of the brain that would be altered. It should be noted that if the stimulation was applied on the scalp, the highly conductive scalp would shunt some of the current. It would require an order of magnitude larger currents to penetrate to the same depth from the scalp surface.

Tripolar TFS has demonstrated efficacy in the modulation of seizure activity induced by several acute models of epilepsy in rats. In pilocarpine-induced status epilepticus, tripolar TFS suppressed convulsive seizures and increased the survival rate (Besio et al., 2007). Similar effects were observed in pentylenetetrazol and penicillin models of seizures (Besio et al., 2010a). Fur- thermore, after tripolar TFS, there was a reduction in highly synchronized brain activity within the beta and gamma bands, suggesting a long-lasting effect of tripolar TFS on brain activity (Besio et al., 2010b).

The antiepileptic mechanisms of stimulation are still under investigation. Past work has shown that stimulation treatments on seizures are due to an increase in GABA neurotransmission (Ladas et al., 2015; Marrosu et al., 2003). Selective GABA-A agonists have been found to reliably retard amygdala kindling (Ebert and Loscher, 1995; Joy et al., 1984; Morimoto et al., 1997). Also, glutamate receptors play a role in regulating limbic seizure activity, NMDA receptors in the thalamus reuniens nucleus participate in the modulation of temporal limbic excitability and seizure development (Hirayasu and Wada, 1992). The ability of tripolar TFS to significantly decrease extracellular glutamate and increase GABA has been described (Santana-Gómez et al., 2015); nevertheless, these changes were strongest when, at the start of ictal activity, increases in the release of glutamate were avoided and GABA release was enhanced during focal seizures, thereby interfering with generalization. This could be the explanation for the positive effects in animals that receive tripolar TFS just after AK.

Moreover, both acute and long-term changes in the network may be at play during chronic stimulation. The time course of the improvement observed in different models of epilepsy or seizures and for different stimulation protocols requires the analysis of other mechanisms related to the plastic process in future works. In this sense, the tripolar TFS after AK effect is manifested in different phases. First, it is observed during tripolar TFS initiation, in which the delay of epileptogenesis is evident (for the full forty-days we applied tripolar TFS); next, the effect is observed by the increase in the length of stage II kindling after tripolar TFS was withdrawn (twenty more days in stage II, and fifty-days to stage VI). These effects are long-lasting, that is, they go beyond the tripolar TFS, and may reflect plastic changes that originate from changes in the inhibition-excitation balance.

\subsection{Effect of tripolar TFS before AK on epileptogenesis development}

Our study shows that tripolar TFS administration prior to AK did not protect against epileptogenesis induced by AK in cats and exerted an enhancement of kindled- seizure duration and frequency. In a previous work (Besio et al., 2013), tripolar TFS application prior to seizure induction showed a trend for anticonvulsive effect. Application of 2-min of tripolar TFS before pilocarpine or pentylenetetrazole induced seizures in rats has been demonstrated to lead to protective effects against neuronal damage and protect against the establishment of SE. However, when tripolar TSF was combined with a sub-effective dose of diazepam there was a significant delay in SE and most animals never reached SE. Additionally, when tripolar TFS was applied before a proconvulsant procedure, it was not enough to modify the afterdischarge threshold in the pilocarpine model (Besio et al., 2013). Similarly, in our results we showed that tripolar TFS administration before AK produced a greater spike duration in stage II, and spike frequency in stages IV and V. Since tripolar TFS before AK increased the severity of seizure signals, it is necessary to research the efficacy, adverse effects, and mechanisms of tripolar TFS.

Future experiments should be designed to elucidate the mechanisms that underlie the effects of tripolar TFS application administered both after and before AK on kindled- seizures described in our experiments by analyzing seizure susceptibility during the kindled-induced postictal period and the involvement of GABA, glutamate and endogenous opioids. Further, tripolar TFS before should be tested when applied over the ipsilateral temporal area like our tripolar TFS after experiments.

In conclusion, tripolar TFS via TCRE applied during seizures over the epileptogenic area reduces seizure severity and retards epileptogenesis in cats. These findings are promising and indicate the need to perform further testing. Since tripolar TFS can be applied non-invasively it would be easier to apply to patients than implantable stimulation methods. 


\section{Funding}

This work was supported by the National Institutes of Health [award 1R21TW009384-01], National Science Foundation [award 1539068], and by the Instituto Nacional de Psiquiatría Ramón de la Fuente Muñiz [award NC123240.1].

\section{Acknowledgements}

We thank Alfredo Martínez and Alejandro Rubio for their technical assistance.

\section{References}

Appleby, B.S., Duggan, P.S., Regenberg, A., Rabins, P.V., 2007. Psychiatric and neuropsychiatric adverse events associated with deep brain stimulation: a meta-analysis of ten years' experience. Mov. Disord. 22, 1722-1728. https://doi.org/10.1002/mds.21551.

Besio, W.G., Koka, K., Cole, A.J., 2007. Effects of noninvasive transcutaneous electrical stimulation via concentric ring electrodes on pilocarpine-induced status epilepticus in rats. Epilepsia 48, 2273-2279. https://doi.org/10.1111/j.1528-1167.2007.01202.x.

Besio, W.G., Gale, K.N., Medvedev, A.V., 2010. Possible therapeutic effects of transcutaneous electrical stimulation via concentric ring electrodes. Epilepsia 51 (Suppl. 3), , 85-87. https://doi.org/10.1111/j.1528-1167.2010.02617.x.

Besio, W.G., Sharma, V., Spaulding, J., 2010. The effects of concentric ring electrode electrical stimulation on rat skin. Ann. Biomed. Eng. 38, 1111-1118. https://doi.org/10. 1007/s10439-009-9891-y.

Besio, W.G., Hadidi, R., Makeyev, O., Luna-Munguía, H., Rocha, L., 2011. Electric fields in hippocampus due to transcranial focal electrical stimulation via concentric ring electrodes. Conf. Proc. IEEE Eng. Med. Biol. Soc. 2011, 5488-5491. https://doi.org/10. 1109/IEMBS.2011.6091400.

Besio, W.G., Liu, X., Wang, L., Medvedev, A.V., Koka, K., 2011. Transcutaneous focal electrical stimulation via concentric ring electrodes reduces synchrony induced by pentylenetetrazole in beta and gamma bands in rats. Int. J. Neural Syst. 21, 139-149. https://doi.org/10.1142/S0129065711002729.

Besio, W.G., Cuellar-Herrera, M., Luna-Munguia, H., Orozco-Suárez, S., Rocha, L., 2013. Effects of transcranial focal electrical stimulation alone and associated with a sub-effective dose of diazepam on pilocarpine-induced status epilepticus and subsequent neuronal damage in rats. Epilepsy Behav. 28, 432-436. https://doi.org/10.1016/j. yebeh.2013.06.021.

Bialer, M., White, H.S., 2010. Key factors in the discovery and development of new antiepileptic drugs. Nat. Rev. Drug Discov. 9, 68-82. https://doi.org/10.1038/ $\operatorname{nrd} 2997$.

Duncan, J.S., Hamani, C., 2015. Stimulating the brain for epilepsy. Neurology 84, 768-769.

Ebert, U., Loscher, W., 1995. Strong induction of c-fos in the piriform cortex during focal seizures evoked from different limbic brain sites. Brain Res. 671, 338-344.

Faria, P., Fregni, F., Sebastião, F., Dias, A.I., Leal, A., 2012. Feasibility of focal transcranial DC polarization with simultaneous EEG recording: preliminary assessment in healthy subjects and human epilepsy. Epilepsy Behav. 25, 417-425. https://doi.org/10.1016/ j.yebeh.2012.06.027.

Fernández-Guardiola, A., Martínez, A., Valdés-Cruz, A., Magdaleno-Madrigal, V.M., Martínez, D., Fernández-Mas, R., 1999. Vagus nerve prolonged stimulation in cats: effects on epileptogenesis (amygdala electrical kindling): Behavioral and electrographic changes. Epilepsia 40, https://doi.org/10.1111/j.1528-1157.1999.tb00787.x.

Fisher, R.S., Velasco, A.L., 2014. Electrical brain stimulation for epilepsy. Nat. Rev. Neurol. 10, 261-270.

Francis, J.T., Gluckman, B.J., Schiff, S.J., 2003. Sensitivity of neurons to weak electric fields. J. Neurosci. 23, 7255-7261. https://doi.org/10.1523/jneurosci.23-19-07255. 2003.

Geddes, L.A., Baker, L.E., 1967. The specific resistance of biological material-a compendium of data for the biomedical engineer and physiologist. Med. Biol. Eng. 5, 271-293. https://doi.org/10.1007/BF02474537.

Gooneratne, I.K., Green, A.L., Dugan, P., Sen, A., Franzini, A., Aziz, T., Cheeran, B., 2016. Comparing neurostimulation technologies in refractory focal-onset epilepsy. J. Neurol. Neurosurg. Psychiatry https://doi.org/10.1136/jnnp-2016-313297, jnnp-2016-313297.

Gorter, J.A., van Vliet, E.A., Lopes da Silva, F.H., 2015. Which insights have we gained from the kindling and post-status epilepticus models?. J. Neurosci. Methods https:// doi.org/10.1016/j.jneumeth.2015.03.025.

Hirayasu, Y., Wada, J.A., 1992. N-methyl-D-aspartate injection into the Massa intermedia facilitates development of limbic kindling in rats. Epilepsia 33, 965-970.

Joy, R.M., Albertson, T.E., Stark, L.G., 1984. An analysis of the actions of progabide, a specific GABA receptor agonist, on kindling and kindled seizures. Exp. Neurol. 83, $144-154$.

Kamida, T., Kong, S., Eshima, N., Abe, T., Fujiki, M., Kobayashi, H., 2011. Transcranial direct current stimulation decreases convulsions and spatial memory deficits following pilocarpine-induced status epilepticus in immature rats. Behav. Brain Res. 217, 99-103. https://doi.org/10.1016/j.bbr.2010.08.050.
Kotagal, P., 2011. Neurostimulation: vagus nerve stimulation and beyond. Semin. Pediatr. Neurol. 18, 186-194. https://doi.org/10.1016/j.spen.2011.06.005.

Kozák, G., Berényi, A., 2017. Sustained efficacy of closed loop electrical stimulation for long-term treatment of absence epilepsy in rats. Sci. Rep. 7, 1-10. https://doi.org/10. 1038/s41598-017-06684-0.

Ladas, T.P., Chiang, C.-C., Gonzalez-Reyes, L.E., Nowak, T., Durand, D.M., 2015. Seizure reduction through interneuron-mediated entrainment using low frequency optical stimulation. Exp. Neurol. 1-13. https://doi.org/10.1016/j.expneurol.2015.04.001.

Löscher, W., 2011. Critical review of current animal models of seizures and epilepsy used in the discovery and development of new antiepileptic drugs. Seizure

Magdaleno-Madrigal, V.M., Valdés-Cruz, A., Martínez-Vargas, D., Martínez, A., Almazán, S., Fernández-Mas, R., Fernández-Guardiola, A., 2002. Effect of electrical stimulation of the nucleus of the solitary tract on the development of electrical amygdaloid kindling in the cat. Epilepsia 43, 964-969. https://doi.org/10.1046/j.1528-1157.2002. 05702.x.

Marrosu, F., Serra, A., Maleci, A., Puligheddu, M., Biggio, G., Piga, M., 2003. Correlation between GABAA receptor density and vagus nerve stimulation in individuals with drug-resistant partial epilepsy. Epilepsy Res. 55, 59-70. https://doi.org/10 1016/S0920-1211(03)00107-4.

Möller, C., Wolf, F., van Dijk, R.M., Di Liberto, V., Russmann, V., Keck, M., Palme, R., Hellweg, R., Gass, P., Otzdorff, C., Potschka, H., 2018. Toward evidence-based severity assessment in rat models with repeated seizures: I. Electrical kindling. Epilepsia 59, 765-777. https://doi.org/10.1111/epi.14028.

Morimoto, K., Sato, H., Yamamoto, Y., Watanabe, T., Suwaki, H., 1997. Antiepileptic effects of tiagabine, a selective GABA uptake inhibitor, in the rat kindling model of temporal lobe epilepsy. Epilepsia 38, 966-974. https://doi.org/10.1111/j.1528-1157. 1997.tb01478.x.

Pitkänen, A., Sutula, T., 2002. Is epilepsy a progressive disorder? Prospects for new therapeutic approaches in temporal-lobe epilepsy. Lancet Neurol. 1, 173-181. https://doi. org/10.1016/S1474-4422(02)00073-X.

Rogel-Salazar, G., Luna-Munguía, H., Stevens, K.E., Besio, W.G., 2013. Transcranial foca electrical stimulation via tripolar concentric ring electrodes does not modify the shortand long-term memory formation in rats evaluated in the novel object recognition test. Epilepsy Behav. 27, 154-158. https://doi.org/10.1016/j.yebeh.2013.01.006.

Rolston, J.D., Englot, D.J., Knowlton, R.C., Chang, E.F., 2016. Rate and complications of adult epilepsy surgery in North America: analysis of multiple databases. Epilepsy Res. 124, 55-62. https://doi.org/10.1016/ j.eplepsyres.2016.05.001.

Rush, S., Driscoll, D.A., 1969. EEG electrode sensitivity-an application of reciprocity. IEEE Trans. Biomed. Eng. 16, 15-22. https://doi.org/10.1109/TBME.1969.4502645.

Ryvlin, P., Cross, J.H., Rheims, S., 2014. Epilepsy surgery in children and adults. Lancet Neurol. 13, 1114-1126. https://doi.org/10.1016/S1474-4422(14)70156-5.

Santana-Gómez, C.E., Alcántara-González, D., Luna-Munguía, H., Bañuelos-Cabrera, I., Magdaleno-Madrigal, V., Fernández-Mas, R., Besio, W., Rocha, L., 2015. Transcranial focal electrical stimulation reduces the convulsive expression and amino acid release in the hippocampus during pilocarpine-induced status epilepticus in rats. Epilepsy Behav. 49, 33-39. https://doi.org/10.1016/j.yebeh.2015.04.037.

Santiago-Rodríguez, E., Cárdenas-Morales, L., Harmony, T., Fernández-Bouzas, A., Porras-Kattz, E., Hernández, A., 2008. Repetitive transcranial magnetic stimulation decreases the number of seizures in patients with focal neocortical epilepsy. Seizure 17 677-683. https://doi.org/10.1016/ j.seizure.2008.04.005.

Sato, M., Racine, R.J., McIntyre, D.C., 1990. Kindling: basic mechanisms and clinical validity. Electroencephalogr. Clin. Neurophysiol. 76, 459-472.

Sato, T., Yamada, N., Morimoto, K., Uemura, S., Kuroda, S., 1998. A behavioral and immunohistochemical study on the development of perirhinal cortical kindling: a comparison with other types of limbic kindling. Brain Res. 811, 122-132.

Shojaei, A., Semnanian, S., Janahmadi, M., Moradi-Chameh, H., Firoozabadi, S.M., Mirnajafi-Zadeh, J., 2014. Repeated transcranial magnetic stimulation prevents kindling-induced changes in electrophysiological properties of rat hippocampal CA1 pyramidal neurons. Neuroscience 280, 181-192. https://doi.org/10.1016/j.neuroscience.2014. 09.022 .

Snider, R., Niemer, W., 1961. A Stereotaxic Atlas of the Cat Brain. University Chicago Press, Chicago.

Theodore, W.H., Fisher, R., 2007. Brain stimulation for epilepsy. Acta Neurochir. Suppl. 3 , 261-272. https://doi.org/10.1007/978-3-211-33081-4-29.

Valdés-Cruz, A., Magdaleno-Madrigal, V.M., Martínez-Vargas, D., Fernández-Mas, R., Almazán-Alvarado, S., 2008. Long-term changes in sleep and electroencephalographic activity by chronic vagus nerve stimulation in cats. Prog. Neuro-Psychopharmacol. Biol. Psychiatry 32, 828-834. https://doi.org/10.1016/j.pnpbp.2007.12.020.

Valdés-Cruz, A., Negrete-Díaz, J.V., Magdaleno-Madrigal, V.M., Martínez-Vargas, D., Fernández-Mas, R., Almazán-Alvarado, S., Torres-García, M.E., Flores, G., 2012. Electroencephalographic activity in neonatal ventral hippocampus lesion in adult rats. Synapse 66, 738-746. https://doi.org/10.1002/syn.21563.

van Oosterom, A., Strackee, J., 1983. Computing the lead field of electrodes with axial symmetry. Med. Biol. Eng. Comput. 21, 473-481.

Wada, J.A., Sato, M., 1974. Generalized convulsive seizures induced by daily electrical stimulation of the amygdala in cats. Correlative electrographic and behavioral features. Neurology 24, 565-574.

Yang, L.X., Jin, C.L., Zhu-Ge, Z.B., Wang, S., Wei, E.Q., Bruce, I.C., Chen, Z., 2006. Unilateral low-frequency stimulation of central piriform cortex delays seizure development induced by amygdaloid kindling in rats. Neuroscience 138, 1089-1096. https://doi. org/10.1016/j.neuroscience.2005.12.006. 